\title{
新型 $\mathbf{Y}\left(\mathbf{P}_{204}\right)_{3}$ 体系催化共聚二氧化碳与环氧丙烷 *
}

二氧化碳与环氧丙烷共聚合成脂肪族聚 碳酸酯是催化固定二氧化碳的有效途径之 一. 这类共聚反应的有效催化剂有二乙基锌 与含活泼氢化合物组成的体系, 如 $\mathrm{ZnEt}_{2}-$
$\mathrm{H}_{2} \mathrm{O}^{[1]}, \mathrm{ZnEt}_{2}$-多元酚等 ${ }^{[2]}$, 但这些催化剂活 性较低, 难以得到高分子量共聚物。李文首 次采用 $\mathrm{Y}\left(\mathrm{P}_{204}\right)_{3}-\mathrm{Al}(i-\mathrm{Bu})_{3}$-丙三醇

$$
\left.\left.\mathrm{P}_{204}=\stackrel{\mathrm{RO}}{\mathrm{RO}}\right\rangle \stackrel{\mathrm{O}}{\mathrm{P}}-\mathrm{O}-, \mathrm{R}=\mathrm{CH}_{3}\left(\mathrm{CH}_{2}\right)_{3} \mathrm{CHCH}_{2}-\right)
$$

三元体系催化剂共聚二氧化碳与环氧丙烷获

得成功:

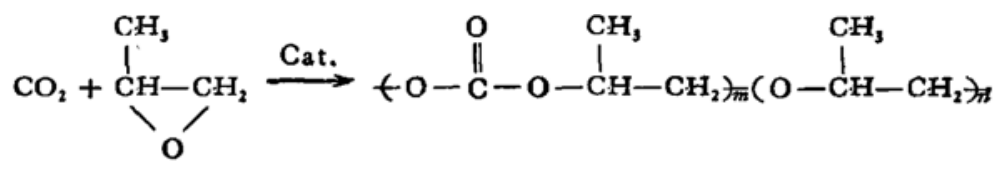

碳酸酯链节

醚链节

聚合反应可在 $1,4-$ 二氧六环、苯、甲苯、四氢 呋喃、环已烷、石油醚等溶剂中进行. 催化剂 的催化效率及共聚物分子量与催化剂三组分 配比、聚合温度、聚合时间等因素有关. 共聚 合的最佳条件为: $\mathrm{Al} / \mathrm{Y}=3$; 丙三醇 $/ \mathrm{Al}=$ $0.4-0.5 ; 60^{\circ} \mathrm{C} ; 1,4-$ 二氧六环作溶剂. 最 大催化效率及产物最大数均分子量分别可达 $2400 \mathrm{~g} / \mathrm{molY} 、 20$ 万.

采用 IR. ${ }^{1} \mathrm{H}-\mathrm{NMR}$ 和 GPC 对 $\mathrm{CO}_{2}$-环氧 丙烷共聚物进行表征: IR $1740 \mathrm{~cm}^{-1}(\mathrm{C}=\mathrm{O}$ 伸缩振动); $1248 \mathrm{~cm}^{-1}$ (碳酸酯链节中 $\mathrm{C}-\mathrm{O}$ 伸缩)； $1050 \mathrm{~cm}^{-1}$ (醚链节中 $\mathrm{C}-\mathrm{O}$ 伸缩). ${ }^{1} \mathrm{H}-\mathrm{NMR}$ 化学位移 $\delta=5.0 \mathrm{ppm}$ (碳酸酯链 节中 $\mathrm{CH}$ 质子); $\delta=4.2 \mathrm{ppm}$ (碳酸酯链节 中 $\left.\mathrm{CH}_{2}\right) ; \delta=3.5$ (醚链节中 $\mathrm{CH}+\mathrm{CH}_{2}$ 吸 收), 由峰面积可求得共聚物中碳酸酯链节含 量为 $10-30 \%$ 。共聚物 GPC 图均为单峰,
说明是共聚物而不是共混物. 分子量分布指 数为 $1.5-2.5$.

产物可用甲醇分级, 甲醇不溶部分可达 $40 \% \sim 75 \%$, 碳酸酯链节摩尔分量为 $30 \%$, 甲醇可溶部分碳酸酯链节含量约为 $10 \%$ 。 甲醇不溶部分共聚物的分子量大于可溶部 分, 分子量分布也较窄. DTA-TGA 分析结 果表明,稀土 $\mathrm{CO}_{2}$-环氧丙烷共聚物具有较高 的热稳定性, 其分解温度大于 $310^{\circ} \mathrm{C}\left(\mathrm{N}_{2}\right.$ 气).

\section{参 考 文 献}

[1] Inoue, S. et al., J.Polym. Sci., Polym. Lett. Ed., 7(1969), 287.

[2] Gorecki, P. et al., J. Polym. Sci., Polym. Lett. Ed., 23(1985).299.

张一烽 陈仙海 沈之荃 (浙江大学化学系, 杭州 310027)

* 国家自然科学基金资助项目. 